\title{
PEMANTAUAN PERTUMBUHAN BAYI MELALUI PELATIHAN PIJAT BAYI SEHAT BAGI KELOMPOK IBU DI KABUPATEN KARAWANG
}

DOI: https://doi.org/10.33024/jkpm.v4i5.4252

\author{
Nelly Apriningrum ${ }^{1}$, Sri Rahayu ${ }^{2}$, Dewi Siti Aisyah ${ }^{3}$ \\ 1,2Program Studi Kebidanan Fakultas Ilmu Kesehatan \\ Universitas Singaperbangsa Karawang, \\ ${ }^{3}$ Program Studi Pendidikan Islam Anak Usia Dini Fakultas Agama Islam \\ Universitas Singaperbangsa Karawang
}

Email korespondensi: nelly.apriningrum@fkes.unsika.ac.id

\begin{abstract}
ABSTRAK
Pertumbuhan pada masa bayi dan balita dapat mengalami gangguan yang dapat menyebabkan berbagai macam kendala pada periode kehidupan selanjutnya. Hasil penelitian memaparkan bahwa permasalahan balita pendek (stunting), kurus (wasting) dan obesitas masih menjadi permasalahan gizi secara nasional, sehingga diperlukan upaya deteksi dini. Beberapa hasil penelitian menyebutkan bahwa tumbuh kembang bayi balita dapat lebih optimal bila dilakukan stimulasi. Upaya stimulasi dapat dilakukan dengan beberapa tindakan diantaranya dengan memberikan permainan edukatif, pemijatan dan SPA yang dapat mengoptimalkan pertumbuhan bayi. Studi pendahuluan di wilayah desa Telagasari didapatkan data bahwa terdapat 2,2 \% balita mengalami stunting dan balita dengan gizi kurang. Tujuan pengabdian masyarakat ini untuk memberikan pengetahuan tentang pertumbuhan bayi dan keterampilan pijat bayi sehat pada ibu-ibu yang memiliki bayi sebagai upaya preventif gangguang pertumbuhan bayi. Metode ceramah tanya jawab digunakan dalam pemaparan pengetahuan, sedangkan pelatihan pijat bayi sehat menggunakan metode demonstrasi. Kegiatan pengabdian dilaksanakan pada bulan maret sampai desember 2020 , dengan jumlah responden 30 peserta ibu yang memiliki bayi usia $\leq 6$ bulan. Melalui kegiatan pengabdian ini peningkatan pengetahuan ibu tentang pijat bayi sehat hingga pengetahuan seluruh responden dalam kategori baik, pengalaman serta keterampilan ibu melakukan pijat pada bayi menjadi $100 \%$ serta peningkatan pertumbuhan bayi rata-rata sebesar 607 gram. Diharapkan kegiatan pengabdian ini dapat dikembangkan di beberapa desa lainnya di Kabupaten Karawang.
\end{abstract}

Kata kunci : Bayi, pertumbuhan, pijat, sehat

\section{ABSTRACT}

Growth during infancy and toddlerhood can experience some issues that can cause various kinds of obstacles in the next life period. Studies show that problems of stunting, wasting and obesity are still national nutritional problems. Therefore, early detection efforts are needed. Results from several 
research show that the growth and development of infants under five can be more optimal when stimulated. Stimulation can be done with several actions including providing educational games, massage and SPA that can optimize baby growth. A preliminary study in the Talagasari village shows that 2,2\% of toddlers were stunted and under five with malnutrition issue. The aim of this community service is for knowledge sharing on infant growth and healthy baby massage skills for mothers who have babies as an effort to prevent baby growth disorders. Question and answer session was done during the knowledge sharing, while massage training for babies were used as a demonstration. Community service activities were carried out from March to December 2020, with respondent number of 30 mothers who had babies aged $\leq 6$ months. . Through this service activity increase the knowledge of all respondents in the good category, the experience and skill of mothers in doing massages on babies to be $100 \%$ and increase in the growth of babies by an average of 607 grams. It hoped that this service activity can be developed in several other villages in Karawang regency.

Keywords: Baby, growth, health, massage

\section{PENDAHULUAN}

Populasi bayi balita sebagai generasi penerus bangsa di Indonesia cukup besar mencapai sekitar $9 \%$ dari populasi penduduk termasuk di Jawa Barat. Sebagai generasi penerus bangsa, kualitas pertumbuhan dan perkembangan bayi balita perlu mendapatkan perhatian serius. Hal ini dapat dilakukan melalui pemantauan secara komprehensif dan berkualitas dengan penyelenggaran stimulasi, deteksi dan intervensi dini penyimpangan tumbuh kembang bayi balita di pelayanan Kesehatan secara berkualitas. Kementerian Kesehatan;2018, Statistik ;2019, Asnafiya et al.,;2020.

Pertumbuhan dan perkembangan bayi dan balita dapat mengalami gangguan yang dapat menyebabkan berbagai macam kendala pada periode kehidupan tumbuh kembang selanjutnya. Hasil penelitian memaparkan bahwa terdapat $16 \%$ balita mengalami gangguan perkembangan, selain itu permasalahan balita pendek (stunting), kurus (wasting) dan obesitas masih menjadi permasalahan gizi secara nasional, sehingga diperlukan upaya deteksi dini penyimpangan pertumbuhan dan perkembangan bayi balita serta tindak lanjut permasalahan yang dihadapi orang tua terkait tumbuh kembang anak Kementerian Kesehatan;2018, Kementerian PPN/Bappenas; 2019.

Beberapa hasil penelitian menyebutkan bahwa tumbuh kembang bayi balita dapat lebih optimal bila dilakukan stimulasi. Upaya stimulasi dapat dilakukan dengan beberapa tindakan diantaranya dengan memberikan permainan edukatif, pemijatan dan SPA yang dapat melatih kekuatan otot, melancarkan peredaran darah, memperbaiki sirkulasi penafasan, pencernaan yang dapat mengoptimalkan pertumbuhan dan perkembangan bayi.

Berbagai hasil penelitian terkait menyebutkan bahwa pijat bayi memberikan efek signifikan terhadap pertumbuhan fisik sebagaimana penelitian yang dilakukan oleh Miftah A yang menghasilkan bahwa terdapat perbedaan yang signifikan perkembangan neonatus pretest dan posttest pada kelompok eksperimen. Andini., et al ; 2014. Penelitian implikasi pijat bayi terhadap pertumbuhan berat badan bayi usia 6-8 bulan dilakukan oleh Prodalima dan Delfriana A pada 12 bayi 
menghasilkan bahwa ada peningkatan berat badan bayi sebesar $1,5 \mathrm{~kg}$. Delfriana \& Prodalima, ;2019.

Pelayanan dan penelitian tentang baby massage, baby gym maupun SPA semakin berkembang dengan maraknya ilmu kesehatan komplementer. Manfaat pemijatan bayi, penting diketahui para orangtua untuk mengoptimalisasikan tumbuh kembang anaknya, terutama masa pandemik Covid-19 yang membutuhkan imunitas tinggi, sebagaimana penelitian bahwa baby massage dapat meningkatkan sistem imunitas bayi prematur yang juga dapat diimplementasikan kepada bayi sehat.Ang et al., ; 2012.

Berdasarkan profil desa tahun 2019 dan studi pendahuluan di wilayah desa Telagasari didapatkan data bahwa terdapat 2,2\% balita mengalami stunting dan balita dengan gizi kurang. Telagasari ; 2019. Keterlibatan berbagai sektor maupun pihak sangat diperlukan untuk mengatasi permasalah tersebut, termasuk orangtua khususnya ibunya, selain dari tenaga kesehatan terkait. Melihat permasalah yang ada, tim dosen kebidanan dan beberapa mahasiswa melakukan upaya pemberdayaan kelompok ibu yang memiliki bayi balita untuk memantau pertumbuhan bayinya serta mengikuti pelatihan pijat bayi sehat sebagai bagian dari upaya preventif penyakit.

\section{MASALAH}

Berdasarkan latarbelakang diatas maka didapatkan rumusan masalah meliputi adanya balita dengan stunting dan satus gizi kurang di wilayah Puskesmas Telagasari Kabupaten Karawang, sehingga dibutuhkan pemberdayaan masyarakat khususnya kelompok ibu agar mampu melakukan pemantauan pertumbuhan bayi dan pijat bayi sehat sebagai upaya pencegahan. Lokasi kegiatan pengabdian dilakukan di desa Telagasari dan desa Kalisari Kecamatan Telagasari Kabupaten Karawang, sebagaimana rekomendasi dari pihak puskesmas dan satgas Covid-19 setempat. Berikut peta lokasi kegiatan pengabdian masyarakat di wilayah puskesmas Telagasari Kabupaten Karawang Jawa Barat.
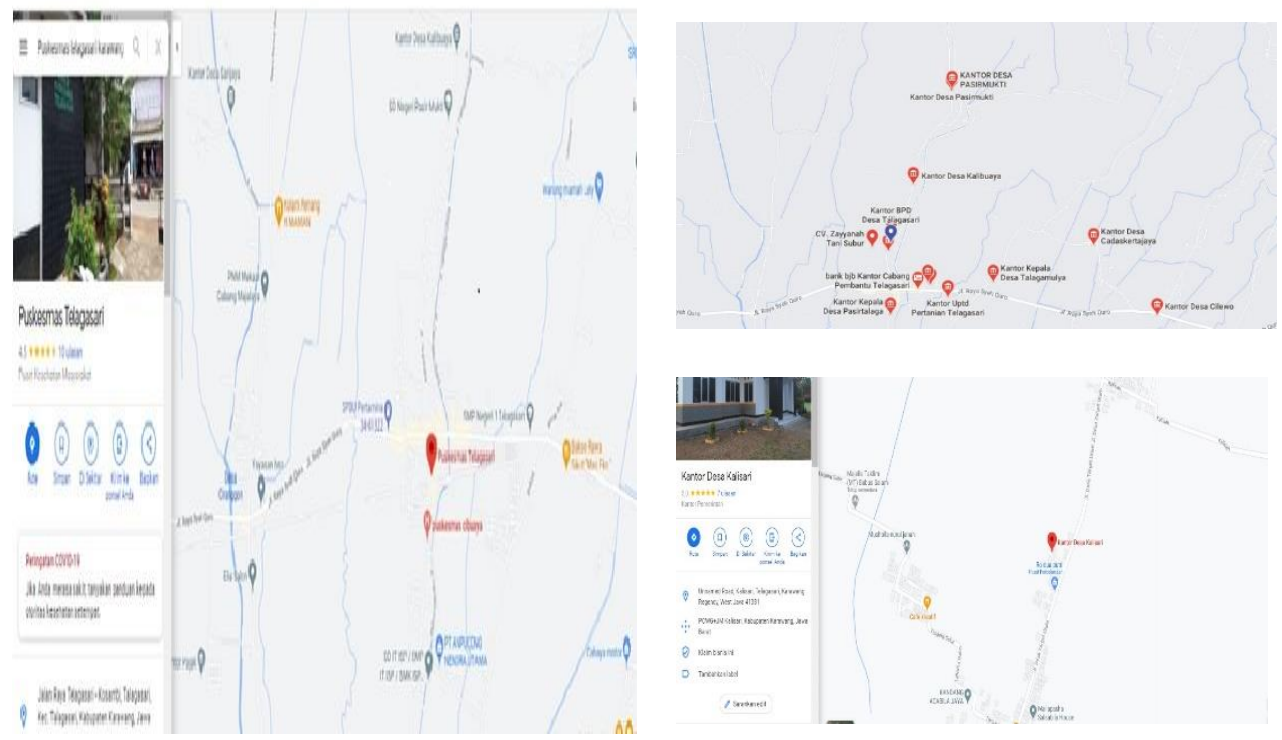

Gambar 1 Peta Lokasi Kegiatan Pengabdian kepada Masyarakat 


\section{METODE}

a. Persiapan

Persiapan sebelum pelaksanaan kegiatan pengabdian masyarakat meliputi persiapan materi, sasaran, tempat, bahan dan alat ;

1) Persiapan materi dengan melakukan studi literatur, membuat materi pelatihan mengenai konsep pertumbuhan dan pijat bayi sehat.

2) Persiapan sasaran melalui identifikasi kelompok ibu yang memiliki bayi usia 1-6 bulan yang akan menjadi responden dalam kegiatan

3) Persiapan materi, alat dan bahan yang akan digunakan dalam kegiatan pengabdian masyarakat.

4) Koordinasi dengan kader untuk menentukan waktu dan tempat serta keterlibatan target sasaran sebagai responden

b. Sasaran

Target sasaran kegiatan pengabdian kepada masyarakat ini adalah kelompok ibu yang memiliki bayi usia $\leq 6$ bulan, dalam keadaan sehat dan berkenan terlibat dalam kegiatan pengabdian masyarakat ini.

c. Implementasi

1) Analisis situasi untuk mengidentifikasi situasi dan kebutuhan yang diperlukan selama pelaksanaan kegiatan pengabdian meliputi persiapan materi, bahan, alat dan tim pelaksana.

2) Identifikasi target sasaran kegiatan dengan melibatkan kader untuk mengidentifikasi ibu yang memiliki bayi usia $\leq 6$ bulan, dalam keadaan sehat untuk menentukan jumlah peserta pelatihan agar tetap memenuhi standar protokol kesehatan.

3) Persiapan waktu dan tempat pelaksanaan kegiatan yang disesuaikan dengan kapasitas jumlah peserta.

4) Menentukan metode pelaksanaan kegiatan dengan menggunakan metode ceramah tanya jawab dan demonstrasi praktik pemantauan pertumbuhan bayi dan cara pijat bayi sehat

5) Melakukan monitoring pemantauan pertumbuhan bayi dan pendampingan ibu untuk memijat bayinya oleh tim pelaksana secara offline dan online.

6) Melakukan evaluasi pelaksanaan pemijatan bayi oleh ibunya dengan pendampingan serta mengevaluasi pertumbuhan bayi pasca pemijatan tahap akhir.

\section{HASIL DAN PEMBAHASAN}

Kegiatan pengabdian kepada masyarakat ini meliputi persiapan, menentukan sasaran, implementasi, monitoring dan evaluasi. Persiapan baik persiapan materi, bahan dan alat dipersiapkan oleh tim pengabdian masyarakat yang terdiri dari dosen prodi kebidanan dan dosen pendidikan islam anak usia dini serta mahasiswa prodi kebidanan Universitas Singaperbangsa Karawang, untuk waktu dan tempat dikoordinasikan dengan kepala desa melalui dengan kader. Hasil analisis situasi dibutuhkan alat dan bahan untuk menunjang keberlangsungan kegiatan pengabdian meliputi ; temperature detector, handsanitizer, timbangan bayi, panthoom dan matras bayi, oil baby massage. Persiapan materi dikemas dalam power point, leaflet 
dan video pijat bayi sehat serta formulir pemantauan. Materi tentang pertumbuhan bayi meliputi konsep tumbuh kembang bayi, ciri - ciri pertumbuhan, faktor yang mempengaruhi tumbuh kembang bayi dan upaya mengoptimalkan tumbuh kembang bayi dimodifikasi dari beberapa referensi. Sedangkan materi dan praktikum pijat bayi sehat meliputi ; konsep dasar baby massage, perbedaan pijat bayi tradisional dan modern, manfaaat dan teknik baby massage. Soetjiningsih \& Ranuh ; 2013, Kusmini, Sutarmi, \& Nurul ; 2018, Julianti; 2018.

Tempat kegiatan pelatihan direkomendasikan oleh kepala desa di kantor kepala desa baik desa Telagasari maupun desa Kalisari. Sasaran dari kegiatan pengabdian ini adalah ibu yang memiliki bayi usia $\leq 6$ bulan, sehat dan berkenan mengikuti pelatihan pijat bayi sehat. Pelaksanaan kegiatan pengabdian masyarakat ini dilakukan pada bulan Oktober sampai desember 2020

Pelaksanaan pengabdian masyarakat diawali dengan sosialisasi yang disampaikan secara langsung untuk memaparkan tujuan kegiatan serta kesepakatan keterlibatan sasaran dalam kegiatan pengabdian sebagai responden dengan menandatangi informed consent. Kegiatan pengabdian masyarakat diikuti oleh 30 responden dan 30 bayi sesuai dengan kriteria sasaran, dengan jumlah 15 responden dari desa Telagasari dan 15 responden dari desa Kalisari. Pelaksanaan sosialisasi dan pelatihan di desa Telagasari dilakukan pada tanggal 18 Otober 2020, sedangkan di desa Kalisari dilakukan pada tanggal 04 November 2020.

Berdasarkan pengumpulan data mengenai pengetahuan responden tentang pijat bayi sehat yang dilakukan sebelum kegiatan pelatihan didapatkan bahwa responden dengan pengetahuan kurang sebesar $93.3 \%$, pengetahuan cukup 3,3\% dan pengetahuan baik sebesar 3,3\%. Data Pengalaman responden yang memiliki pengalaman melakukan pijat pada bayinya sebelum kegiatan pelatihan sebesar $13,3 \%$, sedangkan responden yang tidak memiliki pengalaman melakukan pijat pada bayinya sebanyak $86,7 \%$.

Pelaksanaan kegiatan pengabdian masyarakat ini berupa pelatihan bagi para ibu yang memiliki bayi agar memahami konsep pertumbuhan bayi, mampu memantau pertumbuhan bayinya serta konsep pemijatan bayi sehat dengan menggunakan metode ceramah dan tanya jawab, sedangkan keterampilan cara melakukan pemijatan pada bayi menggunakan metode demonstrasi. Materi pelatihan diberikan secara langsung oleh tim pengabdian 2 dosen prodi kebidanan, 1 dosen PIAUD, 2 bidan yang telah memiliki sertifikat baby massage dan dibantu oleh 4 mahasiswa prodi kebidanan Unsika.

Praktik kemampuan skill pijat bayi sehat dilakukan dengan metode demonstrasi. Langkah demi langkah setiap anggota tubuh pemijatan dipraktekkan dan diikuti peserta pelatihan dengan pendampingan tim pengabdi serta diulang kembali sebagai evaluasi hingga akhir tahapan seluruh anggota tubuh bayi.

Pada akhir kegiatan pelatihan, peserta diberikan penjelasan tentang pakta integritas sebagai bentuk kesepakatan peserta pelatihan untuk berkomitmen melakukan pemijatan pada bayinya dengan pendampingan baik offline maupun online. Hal ini merupakan rencana tindak lanjut kegiatan pelatihan. Peserta pelatihan dibekali formulir pemantauan pertumbuhan bayinya, selain itu leaflet, video baby massage yang dikirim melalui whats app yang dapat digunakan sebagai panduan dalam mempraktekkan pijat pada bayinya. 
Monitoring pijat oleh ibu kepada bayinya dilakukan minimal 1 minggu sekali dengan pendampingan tim pengabdian, sedangkan monitoring berat badan dilakukan pada minggu pertama dan minggu kelima. Monitoring secara langsung dilakukan pada responden desa Telagasari. Berbeda dengan desa Telagasari, monitoring pertumbuhan dan pemijatan ibu kepada bayinya di desa Kalisari dilakukan secara online karena zona orange Covid-19. Metode monitoring secara online ini dilakukan dengan cara pengiriman video dan atau foto pijat bayi oleh ibunya setiap 1 minggu sekali, sedangkan untuk monitoring pertumbuhan dengan mengirimkan foto KMS bayi untuk memantau kenaikan berat badan bayi sebelum dan sesudah dilakukan pijat bayi melalui whatsapp sebagaimana formulir yang telah diberikan.

Hasil monitoring dan evaluasi kegiatan pelatihan didapatkan bahwa terdapat peningkatan pengetahuan responden tentang pijat bayi sehat yang mana seluruh pengetahuan rersponden dalam kategori baik (100\%), dan seluruh responden telah melakukan pijat bayi sehat pada bayinya (100 \%). seluruh responden seluruh peserta pelatihan telah mampu melakukan pemijatan kepada bayinya dengan baik (100\%), Adapun pemantauan pertumbuhan bayi didapatkan hasil kenaikan berat badan sebelum dan sesudah intervensi pijat bayi sebesar 607 gram

Kegiatan pengabdian masyarakat ini telah terlaksana dengan baik dengan berbagai dukungan dari berbagai pihak khususnya pihak mitra, beberapa kendala yang muncul seperti pelaksanaan kegiatan pada kondisi Covid-19 dapat diatasi dengan ijin dari satgas Covid-19 dan puskesmas setempat. Rangkaian kegiatan pengabdian mulai dari sosialisasi, pemaparan materi pelatihan dan praktek pijat bayi, monitoring dan evaluasi telah terlaksana sesuai harapan dan target. Peningkatan pengetahuan kelompok ibu tentang pijat bayi sehat, kemampuan ibu dalam melakukan pemijatan pada bayinya, serta peningkatan pertumbuhan bayi setelah kegiatan pengabdian masyarakat merupakan output dari kegiatan ini. Berikut dokumentasi kegiatan pengabdian masyarakat ini ;
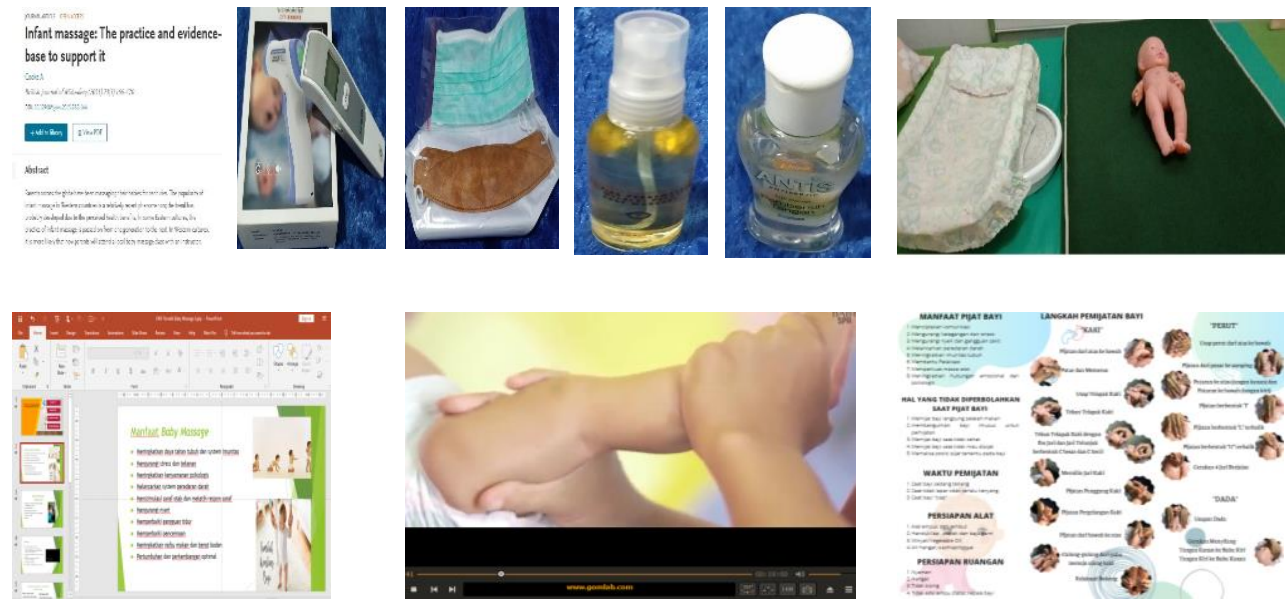

Gambar 2. Persiapan materi, bahan dan alat 

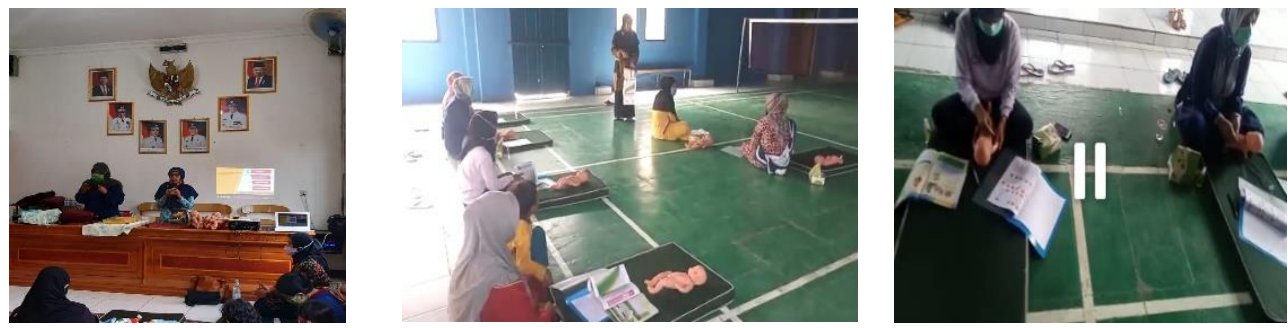

Gambar 3. Kegiatan Sosialisasi dan pelatihan
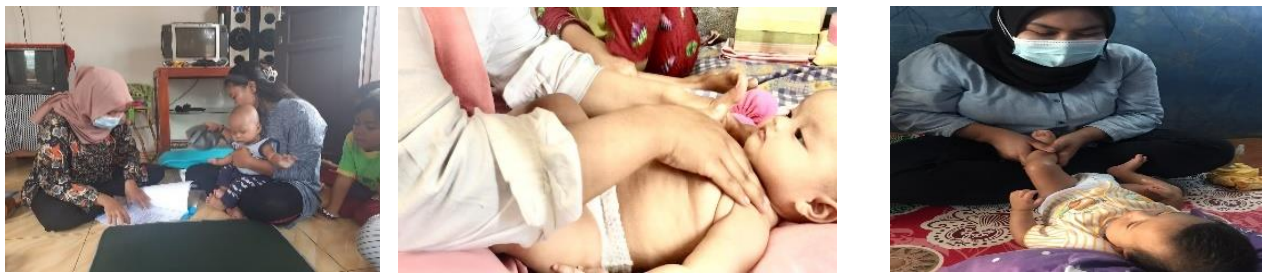

Gambar 4. Monitoring Evaluasi Offline
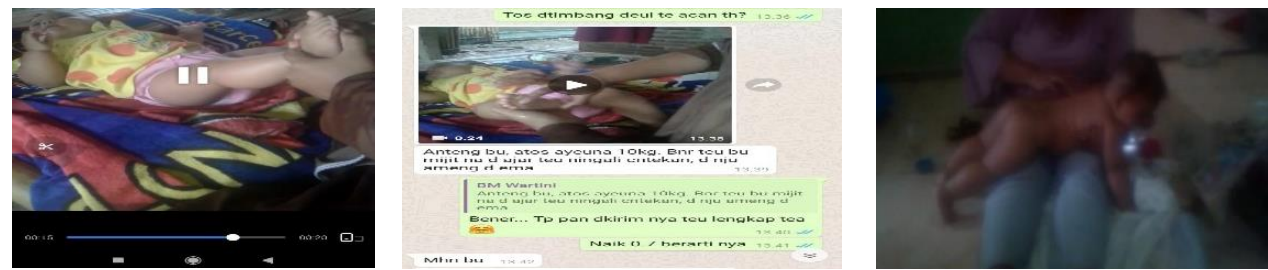

Gambar 5. Monitoring Evaluasi Online

\section{KESIMPULAN}

Kegiatan pengabdian kepada masyarakat ini telah terlaksana dengan baik atas kerjasama dari berbagai pihak. Pelatihan dalam kegiatan ini memberikan implikasi berupa peningkatan pengetahuan responden hingga pengetahuan seluruh responden dalam kategori baik (100\%), peningkatan keterampilan responden melakukan pijat bayi sehat sebanyak $100 \%$, serta peningkatan pertumbuhan bayi rata-rata sebesar 607 gram. Kegiatan pengabdian telah memberikan manfaat bagi responden secara khusus, sehingga kegiatan ini diharapkan dapat dikembangkan di beberapa desa lainnya di wilayah puskesmas Telagasari maupun lainnya di Kabupaten Karawang.

\section{DAFTAR PUSTAKA}

Andini, M., Novayelinda, R., Utami, G. T., \& Utami. ; 2014. Pengaruh Pijat Bayi terhadap Perkembangan Neonatus. JOM PSIK, 1 No 2, 1-9. https://jom.unri.ac.id/index.php/JOMPSIK/article/view/3431/3327

Ang, J. Y., Lua, J. L., Mathur, A., Thomas, R., Asmar, B. I., Savasan, S., ... Shankaran, S. ; 2012. A Randomized Placebo-Controlled Trial of Massage Therapy on The Immune System of Preterm Infants. Pediatrics, 130(6). https://doi.org/10.1542/peds.2012-0196

Asnafiya, A., Vira, W., \& Nani, K. ; 2020. Provinsi Jawa Barat dalam Angka Jawa Barat Province In Figures 2020. (M. Dewi, W. Vira, N. Komalasari, \& 
A. Asnafiya, Eds.) (1st ed.). Jawa Barat: BPS Provinsi Jawa Barat. https://jabarprov.go.id/assets/data/menu/Provinsi\%20Jawa\%20Barat\%20D alam\%20Angka\%202020.pdf

Delfriana, A. A., \& Prodalima. ; 2019. Implikasi Pijat Bayi terhadap Peningkatan Berat Badan pada Bayi Usia 1-6 Bulan. Jurnal Keperawatan Dan Fisioterapi, 1, No 2(2), 1-6.

https://ejournal.medistra.ac.id/index.php/JKF/article/view/136

Julianti. ; 2018. Rahasia Baby SPA Sentuhan Cinta dan Kasih Sayang (1st ed.). Depok.

Kementerian Kesehatan, R. I. ; 2018. Stimulasi Tumbuh Kembang Balita dan Anak Prasekolah. Pedoman Penatalaksanaan Stimulasi, Deteksi, dan Intervensi Dini Tumbuh Kembang Anak Ditingkat Pelayanan Kesehatan Dasar, 128.

Kementerian PPN/Bappenas. ; 2019. Kajian Sektor Kesehatan Pembangunan Gizi di Indonesia. Kementerian PPN/Bappenas.

https://www.bappenas.go.id/files/1515/9339/2047/FA_Preview_HSR_Boo k04.pdf

Kusmini, Sutarmi, \& Nurul, M. ; 2018. Loving Baby Massage (2nd ed.). Semarang: IHCA.

Soetjiningsih, \& Ranuh, I. N. G. ; 2013. Tumbuh Kembang Anak (2nd ed.). Jakarta: EGC.

Statistik, B. P. ; 2019. Statstistik Indonesia Statistical Year Book of Indonesia 2019. Statistik Indonesia 2019 (Indonesian statistics) (1st ed.). Jakarta: Badan Pusat Statistik Indonesia. https://seadelt.net/Asset/Source/Document_ID-329_No-01.pdf

Telagasari, P. ; 2019, Profil Puskesmas Telagasari Kecamatan Telagasari Kabupaten Karawang Tahun 2019. 